\title{
Quality of life of geriatric population in rural block of Haryana
}

\author{
Rajput M. ${ }^{1}$, Pinki $^{2 *}$, Kumar S. ${ }^{3}$, Jaiprakash ${ }^{4}$, Kumar T. $^{\mathbf{5}}$ \\ DOI: https://doi.org/10.17511/ijphr.2019.i5.03
}

1 Meena Rajput, Professor, Department of Community Medicine, Pandit Bhagwat Dayal Sharma Post Graduate Institute of Medical Sciences, Rohtak, Haryana, India.

2* Pinki, PGT Lecturer Economics, Government of Haryana, India.

3 Sunil Kumar, Junior Resident, Department of Community Medicine, Pandit Bhagwat Dayal Sharma Post Graduate Institute of Medical Sciences, Rohtak, Haryana, India.

4 Jaiprakash, Junior Resident, Department of Community Medicine, Pandit Bhagwat Dayal Sharma Post Graduate Institute of Medical Sciences, Rohtak, Haryana, India.

5 Tarun Kumar, Junior Resident, Department of Community Medicine, Pandit Bhagwat Dayal Sharma Post Graduate Institute of Medical Sciences, Rohtak, Haryana, India.

Background: Population ageing refers to increasing share of older persons which has poised to become one of the most significant social transformations of the twenty-first century. This study aims to assess quality of life (QOL) of elderly in rural area. Methods: This was an observational study with cross-sectional design carried out in 400 elderly participants (60 years and above) in a rural area of district Jhajjar, Haryana. WHOQOL-BREF scale was used. Data entry and analysis was performed using SPSS version 20.0. Results: More than half (55\%) of the study participants were in the age group of 60-65 years. $52.5 \%$ participants were females. Mean score of environmental domain was highest $(62.72 \pm 14.18)$, followed by physical health domain $(60.77 \pm 15.82)$. The domain which had the least mean score was social relationships (51.98 \pm 18.61$)$. Mean scores of males in all domains were found higher than females and the difference in mean score was statistically significant $(p<0.05)$, which indicates better QOL of males compared to females. Conclusions: Most of the elderly people (53.8\%) had average quality of life. Most of the females (64.8\%) had average and $47.9 \%$ males had good quality of life. The subjects who were illiterate, financially dependent, having any health problem, of lower socio-economic class, living without partner, unemployed/homemaker had poor quality of life.

Keywords: Elderly, Quality of life, Domains, WHOQOL-BREF

Corresponding Author

Pinki, PGT Lecturer Economics, Government of Haryana, India.

Email: pinkikamlesh98@gmail.com

\section{How to Cite this Article}

Rajput M, Pinki, Kumar S, Jaiprakash, Kumar T. Quality of life of geriatric population in rural block of Haryana. Public Health Rev Int J Public Health Res. 2019;6(5):192-199.

Available From

https://publichealth.medresearch.in/index.php/ijphr/ article/view/119
To Browse

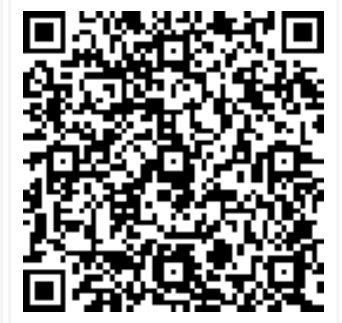

Manuscript Received 2019-10-10-

Conflict of Interest No
Review Round 1 2019-10-20

Funding Nil

$\begin{gathered}\text { Review Round } 2 \\ \text { 2019-10-26 }\end{gathered}$
Ethical Approval
Yes

Review Round 2

Yes
Review Round 3

Accepted 2019-10-30

Plagiarism X-checker $6 \%$

(C) 2019 by Meena Rajput, Pinki, Sunil Kumar, Jaiprakash, Tarun Kumar and Published by Siddharth Health Research and Social Welfare Society. This is an Open Access article licensed under a Creative Commons Attribution 4.0 International License https://creativecommons.org/licenses/by/4.0/ unported [CC BY 4.0]. 


\section{Introduction}

World's population is ageing and virtually every country in the world is experiencing growth in the number and proportion of older persons in their population. Population ageing refers to increasing share of older persons which has poised to become one of the most significant social transformations of the twenty-first century [1]. Ageing is not merely a matter of accumulating years but a process of "adding life to years, not years to life." The world health day theme in 2012 was "Good health adds life to years". Old age cannot be uniformly defined for all, as the concept of ageing carry different meaning in different societies.

The United Nations uses 60 years to refer to older people. But in many developed countries, the age of 65 years is used as a reference point for older persons as this is the age at which persons become eligible for old-age social security benefits [1]. In India, as per the "National Policy on Older People", senior citizen is defined as a person who is 60 years old or above [2]. In 1950, globally 205 million people were aged 60 and above, reaching 810 million in 2012.

Between 2015 and 2030, the number of people in the world aged 60 years or over is projected to grow by 56 per cent, from 901 million to 1.4 billion, and by 2050 , the global population of older persons is projected to be more than double its size in 2015, reaching nearly 2.1 billion [1]. Globally, the number of people aged 80 years or over, the "oldest-old" persons, is growing even faster than the number of older persons overall.

World Health Organization defined quality of life as "an individual's perception of life in the context of culture and value system in which he or she lives and in relation to his or her goals, expectations, standards and concerns" [3].

It is thus a broad concept covering the individual's physical health, mental state, level of independence, social relationships, personal beliefs and their relationship to salient features in the environment [4]. It is evident that the quality of life, in addition to being multidimensional, must take into account the person's life experience, how they feel, and how they interpret their lives. Moreover, current studies suggest that $\mathrm{QOL}$ is more related to a personal sense of happiness and subjective life satisfaction than to objective problems such as physical functioning $[5,6]$.
This trend has made self-ratings of QOL essential, which is consistent with Diener et al statement: "People react differently to the same circumstances, and they evaluate conditions based on their unique expectations, values, and previous experiences" [7].

Support for the subjective measurement of $\mathrm{QOL}$ comes from WHOQOL Scale [8].

\section{Material and Methods}

Type of study: A descriptive cross-sectional study was conducted in area served by CHC Dighal, having 5 PHCs. Out of these PHCs two were selected by simple random sampling and from each PHC, 2 sub centres were selected.

Sample size: The sample size was calculated as 400 subjects using the prevalence of good quality of life in geriatric population to be $34 \%$ and allowable error of $15 \%$ [9]. Sub-centre wise list of geriatric persons who were 60 years and above was prepared with the help of MPHW from village information and survey register. 100 study subjects were selected by simple random sampling from each sub-centre area.

Informed written consent was obtained from the respondent before inclusion in the study. The study subjects were contacted through house to house visit by the investigator himself.

If the investigator was not able to contact the selected subject during two consecutive home visits, another study subject was selected randomly. From each household only one study subject was enrolled for the study.

Data was collected on socio-demographic factors that include age, sex, education, occupation and marital status using a pre-tested semi-structured schedule (Annexure-2).

Socio-economic status was determined using Modified B G Prasad scale [10] and QOL was assessed by using WHOQOL-BREF scale (Annexure3) [3]. The questions of different domains of the instrument were scored according to Likert response scale.

The raw scores of all 4 domains were converted into final scores which lie between 0-100 (the higher the score, the better is the supposed quality of life of elderly for that domain). Overall Quality of life was calculated by sum of final scores of all four domains (Physical, Psychological, Social relationships, Environmental) and converting it into scale of 0-100 [3]. 
Final score (0-100) was further divided into 5 categories to identify level of quality of life in the study (Very Poor: 0-20, Poor: 20-40, Average (Neither poor nor good): 40-60, Good :60-80Very Good: 80-100, ) [11].

Statistical analysis: Data analysis was performed using Statistical Package for Social Sciences (SPSS) version 20.0 software using appropriate tests such as Chi-square.

\section{Results}

Out of 400 study subjects, $52.5 \%$ were females. $73.5 \%$ study subjects belonged to general category and $99.5 \%$ were Hindu by religion. $69.5 \%$ were currently married followed by widowed (29\%). $65.5 \%$ of study subjects were living with partner.

$45.2 \%$ study participants were illiterate while $27 \%$ participants were educated up to primary school, followed by secondary school (18.3\%) and senior secondary school (6.0\%). 50.2\% participants were unemployed/homemaker followed by farmer/people related to agriculture (30.3\%). 24.3\% participants belonged to lower middle class followed by upper lower (23.8\%) and upper middle class (19.7\%).

$37.8 \%$ participants were financially dependent on others for their living. 55\% were currently suffering from any health problem while $22.5 \%$ family members of study participants were suffering from health problem. (Table 1 )

Table-1: Distribution of study subjects by socio-demographic variables $(n=400)$.

\begin{tabular}{|l|l|}
\hline \multicolumn{1}{|c|}{ Socio-demographic variables } & \multicolumn{1}{l|}{ Frequency (\%) } \\
\hline Gender & $190(47.5)$ \\
\hline Male & $210(52.5)$ \\
\hline Female & \multicolumn{2}{l}{} \\
\hline Age group (in years) & $220(55)$ \\
\hline $60-65$ & $69(17.3)$ \\
\hline $65-70$ & $62(15.5)$ \\
\hline $70-75$ & $20(5.0)$ \\
\hline $75-80$ & $29(7.2)$ \\
\hline$>80$ & \multicolumn{2}{|l}{} \\
\hline Caste & $294(73.5)$ \\
\hline General & $59(14.8)$ \\
\hline Backward Classes & $47(11.8)$ \\
\hline Scheduled Castes/scheduled Tribes & $398(99.5)$ \\
\hline Religion & $2(0.5)$ \\
\hline Hindu & $0(0)$ \\
\hline Muslim & \\
\hline Sikh &
\end{tabular}

\begin{tabular}{|c|c|}
\hline Christian & $0(0)$ \\
\hline \multicolumn{2}{|l|}{ Marital status } \\
\hline Single/ Unmarried & $2(0.5)$ \\
\hline Married & $278(69.5)$ \\
\hline Separated & $1(0.3)$ \\
\hline Divorced & $3(0.8)$ \\
\hline Widowed & $116(29.0)$ \\
\hline \multicolumn{2}{|l|}{ Type of family } \\
\hline Joint & $295(73.8)$ \\
\hline Nuclear & $105(26.2)$ \\
\hline \multicolumn{2}{|l|}{ Education } \\
\hline Post-graduation and above & $2(0.5)$ \\
\hline Graduation / Professional degree & $12(3.0)$ \\
\hline Senior secondary & $24(6.0)$ \\
\hline Secondary & $73(18.3)$ \\
\hline Primary & $108(27.0)$ \\
\hline Illiterate & $181(45.2)$ \\
\hline \multicolumn{2}{|l|}{ Occupation } \\
\hline Unemployed \& Housewife & $201(50.2)$ \\
\hline Agriculture / Farmer & $121(30.3)$ \\
\hline Retired & $29(7.2)$ \\
\hline Shopkeeper & $9(2.3)$ \\
\hline Laborer & $11(2.8)$ \\
\hline Private work & $29(7.2)$ \\
\hline \multicolumn{2}{|l|}{ Socioeconomic Status } \\
\hline Upper & $73(18.2)$ \\
\hline Upper middle & 79 (19.7) \\
\hline Lower middle & $97(24.3)$ \\
\hline Upper lower & $95(23.8)$ \\
\hline Lower & $56(14.0)$ \\
\hline Living with partner & $263(65.5)$ \\
\hline Residing with children & 355 (88.5) \\
\hline Financial dependent & $151(37.8)$ \\
\hline Having any health problem & $220(55.0)$ \\
\hline Family member having any health problem & $90(22.5)$ \\
\hline
\end{tabular}

Mean score of environmental domains was highest $(62.72 \pm 14.18)$, followed by physical health (60. $77 \pm 15.82)$. The domain which had least mean score was social relationships (51.98 18.61$)$ (Table 2)

Table-2: Mean scores of individual domains $(n=400)$.

\begin{tabular}{|l|l|l|}
\hline \multicolumn{1}{|c|}{ Domain } & \multicolumn{1}{c|}{ Mean score } & \multicolumn{1}{c|}{ Standard deviation } \\
\hline Physical health & 60.77 & 15.815 \\
\hline Psychological & 52.18 & 13.084 \\
\hline Social relationships & 51.98 & 18.611 \\
\hline Environmental & 62.72 & 14.180 \\
\hline
\end{tabular}

$53.2 \%$ males had either good or very good QOL as compared to $25.3 \%$ females and the association of QOL with gender was found statistically significant $(p<0.05)$. 
$51.7 \%$ of study participants in general category, $49.2 \%$ in backward classes, $72.3 \%$ in schedule castes/schedule tribes had average QOL. Statistically significant association was observed between QOL and caste ( $\mathrm{p}<0.05$ ). 65.5\% participants were living with partners.

Among them $48.7 \%$ had average QOL followed by $41.1 \%$ who had good quality of life. $24.8 \%$ had good quality of life who were living without partner. A statistically significant association $(p<0.05)$ was found between QOL and living with partner. 75\% study participants who were graduate and above had good QOL. Association of QOL with education was found
Statistically significantly associated ( $p<0.05$ ). $55.2 \%$ retired persons, $55.6 \%$ shopkeepers, $55.2 \%$ private workers and $18.2 \%$ labourers had good QOL. $53.4 \%$ study participants who belongs to upper class also had good QOL. The association of quality of life with occupation and socio-economic status of participants was found statistically significant. $(p<0.05)$.

$11.9 \%$ participants who were financially decadents had poor quality of life as compared to $9.1 \%$ having poor QOL due to health problems. Quality of life is associated statistically significant with financial dependency and any health problem along with duration of health problem. $(p<0.05)$ (Table 3$)$.

Table-3: Association of quality of life (QOL) with socio-demographic factors

\begin{tabular}{|c|c|c|c|c|c|c|c|c|c|c|c|c|c|c|}
\hline \multirow[t]{3}{*}{ Socio-demographic factors } & \multicolumn{10}{|c|}{ Quality of life (QOL) } & \multirow{2}{*}{\multicolumn{2}{|c|}{ Total }} & \multirow[t]{3}{*}{ Chi-square } & \multirow[t]{3}{*}{$P$ value } \\
\hline & \multicolumn{2}{|c|}{ Very poor } & \multicolumn{2}{|c|}{ Poor } & \multicolumn{2}{|c|}{ Average } & \multicolumn{2}{|c|}{ Good } & \multicolumn{2}{|c|}{ Very good } & & & & \\
\hline & $n$ & $\%$ & $n$ & $\%$ & $n$ & $\%$ & n & $\%$ & n & $\%$ & n & $\%$ & & \\
\hline \multicolumn{15}{|l|}{ Sex } \\
\hline Male & 0 & 0.0 & 10 & 5.3 & 79 & 41.6 & 91 & 47.9 & 10 & 5.3 & 190 & 100 & \multirow[t]{2}{*}{35.13} & \multirow[t]{2}{*}{$p<0.05$} \\
\hline Female & 1 & 0.5 & 20 & 9.5 & 136 & 64.8 & 51 & 24.3 & 2 & 1.0 & 210 & 100 & & \\
\hline \multicolumn{15}{|l|}{ Caste } \\
\hline 'General & 0 & 0.0 & 23 & 7.8 & 152 & 51.7 & 109 & 37.1 & 10 & 3.4 & 294 & 100 & \multirow{3}{*}{25.82} & \multirow{3}{*}{$p<0.05$} \\
\hline Backward classes & 0 & 0.0 & 1 & 1.7 & 29 & 49.2 & 27 & 45.8 & 2 & 3.4 & 59 & 100 & & \\
\hline Schedule castes/schedule tribes & 1 & 2.1 & 6 & 12.8 & 34 & 72.3 & 6 & 12.8 & 0 & 0.0 & 47 & 100 & & \\
\hline \multicolumn{15}{|l|}{ Living with partner } \\
\hline Yes & 0 & 0.0 & 17 & 6.5 & 128 & 48.7 & 108 & 41.1 & 10 & 3.8 & 263 & 100 & \multirow[t]{2}{*}{15.05} & \multirow[t]{2}{*}{$p<0.05$} \\
\hline No & 1 & 0.7 & 13 & 9.5 & 87 & 63.5 & 34 & 24.8 & 2 & 1.5 & 137 & 100 & & \\
\hline \multicolumn{15}{|l|}{ Education } \\
\hline Post-graduation and above & 0 & 0.0 & 0 & 0.0 & 0 & 0.0 & 2 & 100 & 0 & 0.0 & 2 & 100 & \multirow{6}{*}{72.08} & \multirow{6}{*}{$p<0.05$} \\
\hline Graduation and above & 0 & 0.0 & 0 & 0.0 & 1 & 8.3 & 9 & 75.0 & 2 & 16.7 & 12 & 100 & & \\
\hline Sr. secondary & 0 & 0.0 & 4 & 16.7 & 9 & 37.5 & 9 & 37.5 & 2 & 8.3 & 24 & 100 & & \\
\hline Secondary & 0 & 0.0 & 0 & 0.0 & 29 & 39.7 & 40 & 54.8 & 4 & 5.5 & 73 & 100 & & \\
\hline Primary & 0 & 0.0 & 4 & 3.7 & 59 & 54.6 & 41 & 38.0 & 4 & 3.7 & 108 & 100 & & \\
\hline Illiterate & 1 & 0.6 & 22 & 12.2 & 117 & 64.6 & 41 & 22.7 & 0 & 0.0 & 181 & 100 & & \\
\hline \multicolumn{15}{|l|}{ Occupation } \\
\hline Unemployed / Homemaker & 1 & 0.5 & 18 & 9.0 & 126 & 62.7 & 55 & 27.4 & 1 & 0.5 & 201 & 100 & \multirow{6}{*}{51.40} & \multirow{6}{*}{$p<0.05$} \\
\hline Agriculture / Farmer & 0 & 0.0 & 11 & 9.1 & 58 & 47.9 & 48 & 39.7 & 4 & 3.3 & 121 & 100 & & \\
\hline Retired & 0 & 0.0 & 1 & 3.4 & 8 & 27.6 & 16 & 55.2 & 4 & 13.8 & 29 & 100 & & \\
\hline Shopkeeper & 0 & 0.0 & 0 & 0.0 & 4 & 44.4 & 5 & 55.6 & 0 & 0.0 & 9 & 100 & & \\
\hline Labourer & 0 & 0.0 & 0 & 0.0 & 9 & 81.8 & 2 & 18.2 & 0 & 0.0 & 11 & 100 & & \\
\hline Private work & 0 & 0.0 & 0 & 0.0 & 10 & 34.5 & 16 & 55.2 & 3 & 10.3 & 29 & 100 & & \\
\hline Socio-economic status & & & & & & & & & & & & & & \\
\hline Upper & 1 & 1.4 & 4 & 5.5 & 29 & 39.7 & 39 & 53.4 & 0 & 0.0 & 73 & 100 & 41.95 & $p<0.05$ \\
\hline Upper Middle & 0 & 0.0 & 2 & 2.5 & 42 & 53.2 & 29 & 36.7 & 6 & 7.6 & 79 & 100 & & \\
\hline Lower Middle & 0 & 0.0 & 5 & 5.2 & 58 & 59.8 & 30 & 30.9 & 4 & 4.1 & 97 & 100 & & \\
\hline Upper Lower & 0 & 0.0 & 15 & 15.8 & 48 & 50.5 & 30 & 31.6 & 2 & 2.1 & 95 & 100 & & \\
\hline Lower & 0 & 0.0 & 4 & 7.1 & 38 & 67.9 & 14 & 25.0 & 0 & 0.0 & 56 & 100 & & \\
\hline
\end{tabular}


Rajput M. et al: Quality of life of geriatric population

\begin{tabular}{|c|c|c|c|c|c|c|c|c|c|c|c|c|c|c|}
\hline \multicolumn{15}{|c|}{ Financial dependency } \\
\hline Yes & 0 & 0.0 & 18 & 11.9 & 87 & 57.6 & 45 & 29.8 & 1 & 0.7 & 151 & 100 & \multirow[t]{2}{*}{14.24} & \multirow[t]{2}{*}{$p<0.05$} \\
\hline No & 1 & 0.4 & 12 & 4.8 & 128 & 51.4 & 97 & 39.0 & 11 & 4.4 & 249 & 100 & & \\
\hline \multicolumn{15}{|c|}{ Having any health problem } \\
\hline Yes & 1 & 0.5 & 20 & 9.1 & 138 & 62.7 & 59 & 26.8 & 2 & 0.9 & 220 & 100 & \multirow[t]{2}{*}{27.30} & \multirow[t]{2}{*}{$p<0.05$} \\
\hline No & 0 & 0.0 & 10 & 5.6 & 77 & 42.8 & 83 & 46.1 & 10 & 5,6 & 180 & 100 & & \\
\hline \multicolumn{15}{|c|}{ Duration of health problem } \\
\hline$<1$ & 1 & 2.5 & 1 & 2.5 & 28 & 70.0 & 10 & 25.0 & 0 & 0.0 & 40 & 100 & \multirow{4}{*}{46.16} & \multirow{4}{*}{$p<0.05$} \\
\hline $1-5$ & 0 & 0.0 & 9 & 11.0 & 50 & 61.0 & 23 & 28.0 & 0 & 0.0 & 82 & 100 & & \\
\hline $5-10$ & 0 & 0.0 & 4 & 8.9 & 29 & 64.4 & 12 & 26.7 & 0 & 0.0 & 45 & 100 & & \\
\hline$>10$ & 0 & 0.0 & 7 & 13.2 & 32 & 60.4 & 12 & 22.6 & 2 & 0.0 & 53 & 100 & & \\
\hline
\end{tabular}

\section{Discussion}

The present study was conducted to determine the quality of life of geriatric population in rural block of Haryana. The mean age of the study participants was $66.98 \pm 6.89$ years. Similar finding was reported by Hameed $\mathrm{S}$ et al (2014, Karnataka) in which they reported mean age of study participants as $66.86 \pm 6.3$ year [12].

In the present study, it was observed that mean score of environmental domain was highest $(62.72 \pm 14.18)$, followed by physical health $(60.77 \pm 15.82)$. The domain which had the least mean score was social relationships (51.98 18.61$)$.

The highest mean score in environmental QOL may be due to pollution free, stress free and greener environment in rural areas. As Haryana is among better performing state in India better financial resources, adequate diet, home environment and participation in recreation/leisure activities of elderly makes better environmental and physical health domain of QOL.

In the present study, $35.5 \%$ elderly were having good and $3 \%$ had very good QOL whereas $53.8 \%$ elderly had average quality of life (QOL). Similar to these findings Sowmiya KR et al (2012, Tamil Nadu) observed $42.4 \%$ good and $3.8 \%$ very good and Rajasi RS et al (2016, Kerala) reported $38.8 \%$ good and $2.5 \%$ very good QOL in their studies $[13,14]$.

The present study showed that $47.9 \%$ males had good quality of life as compared to females (24.3\%). In accordance to this finding, Van Nguyen T et al (2017, Vietnam) and Dasgupta A et al (2018, West Bengal) found that overall QOL of males are better and statistically significant than females ( $p<$ $0.01)[15,16]$.
The results may be due to the fact that, it is believed that Indian society is male dominant and male enjoys greater decision-making power compared to females which gives them more chances to involve in recreational/leisure activities.

Present study showed that elderly belonging to general category were $40.5 \%$, belonging to backward classes were $49.2 \%$ and $12.8 \%$ belonged to schedule caste had good and very good QOL. A statistically significant association was observed between quality of life and caste of study participants $(p<0.05)$.

Qadri S et al (2013, Haryana) in their study also observed similar finding i.e. significant association was between QOL and caste of study subject. [17] $55.2 \%$ retired persons, $55.2 \%$ private workers, $55.6 \%$ shopkeepers and $18.2 \%$ labourers had good QOL $(p<0.05)$.

Qadri S et al (2013, Haryana) also found that QOL was statistically significant with different occupations. [17] $53.4 \%$ study participants who belongs to upper class had good QOL, $53.2 \%, 59.8 \%, 50.5 \% 67.9 \%$ elderly who belongs to upper middle, lower middle, upper lower and lower respectively had average QOL.

The association of quality of life with occupation and socio-economic status of participants was found statistically significant. This may be explained as high SES is directly associated with high income which in turn helps to avail better accommodation, adequate diet and medical facilities leading to live a better QOL. $(p<0.05)$

Study participants who were post graduate and above had good quality of life, $75 \%$ study participants who were graduate and above had good QOL. 54.8\% had good QOL who possess secondary education. $54.6 \%$ primary and $64.6 \%$ illiterates had average QOL respectively. 
QOL and education was found statistically significantly associated ( $p<0.05$ ). Similar results were observed by Kumari R et al (2018, Jammu) [18] in their study where they find QOL statistically associated with education. Sowmiya KR et al (2102, Tamil Nadu) [13] also observed that literates had better QOL compared to illiterates.

Naing MM et al (2010, Myanmar) observed statistically significant association between QOL and education. [19] Kaur $\mathrm{H}$ et al (2015, Uttarakhand) also showed similar results. Qadri S et al (2013, Haryana), George S et al (2016, Kerala), Kritika et al (2017, Uttarakhand) and Dasgupta A et al (2018, West Bengal) in their studies also showed statistically significant association between QOL and education $[16,17,20,21,22]$.

This can be explained by the fact that they have a better access to information and health care system which adds to their QOL. 65.5\% elderly were living with partner, and among them $48.7 \%$ had average QOL followed by $41.1 \%$ having good quality of life. Quality of life was good in $24.8 \%$ study subjects who were living without partner.

A statistically significant association $(p<0.05)$ was found between QOL and living with partner. This can be explained by the fact that elderly married living with their partner is being more socially acceptable which leads to enhance their chances to create more social relationships.

$11.9 \%$ financially dependent participants had poor quality of life compared to $4.8 \%$ non-dependents. Similar to these findings, Kaur $\mathrm{H}$ et al (2015, Uttarakhand), Dasgupta A et al (2018, West Bengal), and Kritika et al (2017, Uttarakhand) also observed significant association between QOL and financial dependency $[16,20,22]$.

9.1\% participants who were having any health problem had poor QOL as compared to $5.6 \%$ participants having no health problems ( $<<0.05)$. Quality of life is associated statistically significant with financial dependency and health problems of study participants ( $p<0.05$ ). This may be due to the fact that financial independency brings the power of autonomy, opportunities to fulfil the needs in an independent and more satisfactory way which might explain the better QOL. Kumari R et al (2018, Jammu), Naing MM et al (2010, Myanmar), Kaur H et al (2015, Uttarakhand) in their study find QOL statistically associated with health problem of study participants. [18,19,20].
Presence of health problems can cause physical dependency which limits movements and in turn can lead to economic dependency and psychological ill health, this results in poor QOL. It has been observed that QOL is statistically associated with sex, caste, living with partner, level of education, occupation, socio-economic status, financial dependency, health problem and duration of health problem of study participants.

\section{Limitations}

Sample size was less and only restricted to rural elderly so results can't be generalized to whole population. Unknown confounders might have affected the results because quality of life is multidimensional. Increased chances of recall bias in the present study as it deals with elderly population.

\section{Conclusion}

Most of the elderly people had average quality of life. Males had better quality of life compared to females. Those who were living with partner, had higher education and higher SES had better quality of life. Elderly who were financially dependent to others or having any health problem had poor quality of life.

Social support from family members is essential so that elderly receive the much-needed practical help which in turn helps them in neutralizing the stress of living with ageing.

\section{What the study adds to the existing knowledge}

The present study highlights the need of skill identification in elderly and provision of appropriate pension as well as vocational jobs like knitting for elderly women, freelance writer, tutor, financial advisor etc., to decrease dependence. National Program for Healthcare of Elderly (NPHCE) is a fullfledged program to answer issues faced by elderly but the implementation of this program is far from complete. So, this study emphasizes on the need of further studies to evaluate the implementation of programs for elderly and using different new approaches to increase the quality of life in elderly.

\section{Author's contribution}

Dr. Meena Rajput: Guiding author, Idea for the study 
Pinki: Data Collection, Data entry, Analysis of the data, paper writing and final editing

Dr. Sunil Kumar: Principal investigator (involved in each step of the study like planning and protocol writing, data collection, analysis, paper writing etc.)

Dr. Jaiprakash: Data Entry and Final Editing

Dr. Tarun Kumar: Protocol writing, Analysis of data, final editing and Peer review

\section{Reference}

01. World Population Ageing. Population Division 1950-2050. New York- Department of Economic and Social Affairs, United Nations. 2015.

[Crossref]

02. Ministry of Statistics \& Programme Implementation, Government of India. Situation Analysis of the elderly in India. New DelhiCentral Statistics Office. 2011.

[Crossref]

03. World Health Organization. WHOQOL-BREFIntroduction, Administration, Scoring and Generic Version of the Assessment, Programme on mental health. Geneva, WHO. 1996.

[Crossref]

04. Gill TM, Feinstein AR. A Critical Appraisal of the Quality of Quality-of-Life Measurements. JAMA. 1994; 272(8)619-626. doi:10.1001/jama.1994.03520080061045 [Crossref]

05. Khan MN, Mondal MNI, Hoque N, Islam MS, Shahiduzzaman M. A Study on Quality of Life of Elderly Population in Bangladesh. Am J Health Res. $2014 ; 2(4) 152-57$.

doi: $10.11648 / j . a j h r .20140204 .18 \quad$ [Crossref]

06. Akbar F, Kumar M, Das N, Chatterjee S, Mukhopadhyay S, Chakraborty M et al. Quality of Life (QOL) Among Geriatric Population in Siliguri Sub-division of District Darjeeling, West Bengal. Nat J Res Com Med. 2013;2(1)17-22. [Crossref]

07. Diener E, Suh EM, Lucas RE, Smith HL. Subjective well-being- three decades of progress. Psychol Bull. 1999;125(2)276-302. doi: 10.1037/0033-2909.125.2.276

[Crossref]
08. Power M, Harper A, Bullinger M. The World Health Organization WHOQOL-100- Tests of the universality of quality of life in 15 different cultural groups worldwide. Health Psychol. $1999 ; 18(5) 495-505$.

doi: [Article] [Crossref]

09. Anand B, Shukla M, Ahmad S, Soni S. Dimensions and determinants of Quality of Life among elderly in a rural population of Barabanki District, Uttar Pradesh. Indian J Foren Comm Med. 2017;4(1)1-6.

doi: 10.18231/2394-6776.2017.0001 [Crossref]

10. Pandey VK, Aggarwal P, Kakkar R. Modified BG Prasad's Socio-economic Classification-2018The need of an update in the present scenario. Indian J Comm Health. 2018;30(1)82-84. [Crossref]

11. Gupta A, Mohan U, Tiwari SC, Singh SK, Singh VK. Quality of Life of Elderly People and Assessment of Facilities Available in Old Age Homes of Lucknow, India. Natl J Community Med. 2014;5(1)21-24.

doi: $10.13140 / 2.1 .1289 .2807$ [Crossref]

12. Hameed S, Brahmbhatt KR, Patil DC, Prasanna $K S$, Jayaram $S$. Quality of life among the geriatric population in a rural area of Dakshina Kannada, Karnataka, India. GJMEDPH. 2014;3(3)1-5.

[Crossref]

13. Sowmiya KR, Nagarani. A Study on Quality of Life of Elderly Population in Mettupalayam, A Rural Area of Tamilnadu. Nat J Res Com Med. 2012;1(3)139-143.

doi: $10.26727 /$ NJRCM.2012.1.3.139-143 [Crossref]

14. Rajasi RS, Mathew T, Nujum ZT, Anish TS, Ramchandran R, Lawrence T. Quality of life and sociodemographic factors associated with poor quality of life in elderly women in Thiruvananthpuram, Kerala. Indian J Public Health. 2016;60(3)210-215.

doi: 10.4103/0019-557X.189016 [Crossref]

15. Nguyen TV, Nguyen HV, Nguyen TD, Nguyen TV, Nguyen PT. Difference in quality of life and associated factors among the elderly in rural Vietnam. J Prev Med Hyg. 2017;58(1)E63-E71. [Crossref] 
16. Dasgupta A, Pan T, Paul B, Bandopadhyay L, Mandal S. Quality of life of elderly people in a rural area of West Bengal- A community-based study. Med J DY Patil Vidyapeeth. 2018;11(6):527-531.

doi: 10.4103/mjdrdypu.mjdrdypu_78_18 [Crossref]

17. Qadri S, Ahluwalia SK, Ganai A, Bali S, Wani F, Bashir $\mathrm{H}$. An epidemiological study on quality of life among rural elderly population of northern india. Int $\mathrm{J}$ Med Sci Public Health. 2013;2(3)514-522.

doi: $\quad 10.5455 /$ ijmsph.2013.2.492-500 [Crossref]

18. Kumari R, Dewan D, Langer B, Gupta RK, Singh $\mathrm{P}$, Anuradha. Quality of Life and Its Associated Factors- A Comparative Study among Rural and Urban Elderly Population of North India. Natl J Community Med. 2018;9(6)420-425.

[Crossref]
19. Naing MM, Nanthamongkolchai S, Munsawaengsub C. Quality of Life of the Elderly People in Einme Township Irrawaddy Division, Myanmar. Asia J Public Health. 2010;1(2)4-10. [Crossref]

20. Kaur $H$, Kaur $H$, Venkateashan $M$. Factors determining family support and quality of life of elderly population. Int J Med Sci Public Health. 2015;4(8)1049-1053.

doi: $10.5455 /$ ijmsph.2015.21012015220 [Crossref]

21. George S, Leemamoni K, Paul N. Determinants of Quality of life of Elderly in A Rural Population Of Kerala, India. Nat J Res Comm Med. 2016;5(1)46-51.

[Crossref]

22. Kritika, Kakkar R, Aggarwal P, Semwal J. Quality of Life (QOL) among the Elderly in Rural Dehradun. Indian J Comm Health. 2017;29(1)39-45.

[Crossref] 